Motrivivência $\quad$ v. 28, n. 48, p. 331-346, setembro/2016

\title{
A CULTURA DE PAZ NA PERCEPÇÃO DOS PROFESSORES DE EDUCAÇÃO FÍSICA DE UMA ESCOLA DA REDE ESTADUAL DE ENSINO DO RIO GRANDE DO SUL
}

José Paulo Reichenbach? Denise Grosso da Fonseca ${ }^{2}$

\section{RESUMO}

O presente trabalho objetiva compreender como o professor de Educação Física percebe a promoção da cultura de paz no ambiente escolar. O referencial teórico analisa o fenômeno da violência, a violência escolar e suas nuances. Também trata da promoção da cultura de paz, a partir de uma visão que acredita que, se a cultura da violência se constrói cultural e socialmente, a cultura de paz pode vir a ser construída, a partir de ações intencionais. É uma pesquisa qualitativa, desenvolvida através de entrevistas, observações e análise de documentos. Constata-se que os professores são conhecedores da Cultura de paz, mas ações objetivas e intencionais nessa direção, ainda não são desenvolvidas.

Palavras-chave: Educação Física; Cultura de Paz; Violência Escolar

1 Pós-graduando em Organização do Trabalho Pedagógico: orientação, supervisão e gestão escolar. Centro Universitário Internacional (UNINTER). Porto Alegre/Rio Grande do Sul, Brasil. E-mail: zepaulop@outlook.com

2 Doutora em Educação. Professora da Escola de Educação Física, Fisioterapia e Dança da Universidade Federal do Rio Grande do Sul (ESEFID - UFRGS). Porto Alegre/Rio Grande do Sul, Brasil. E-mail: dgf.ez@terra.com.br 


\section{INTRODUÇÃO}

Período de estágio curricular. Uma ligação da professora orientadora: "não teremos aula à tarde. Ocorreu um incidente na escola, com arma de fogo, pela parte da manhã".

Pensando na violência no seu sentido global, deparamo-nos com os constantes conflitos que emergem em vários lugares do mundo. Desde os conflitos globais, como o da faixa de Gaza entre Israel e Hamas, até homicídios, assaltos, furtos, roubos,mais próximos de nós etc. No Brasil, de acordo com o material distribuído pela Secretaria Geral da Presidência, elaborado por Waiselfisz (2013), os homicídios são hoje a principal causa de morte de jovens de 15 a 24 anos. Nessa perspectiva, Malta et al. ${ }^{3}$ (apud NETTO-MAIA et al., 2013, p. 798) afirmam que, "a violência já é considerada um problema de saúde pública, uma vez que expressa importante carga ao adoecimento da população, impactando sobre as taxas de morbimortalidade na saúde individual e coletiva".

Voltando nosso olhar para o contexto educacional, em pesquisa realizada com professores na rede estadual de SP constatou-se que 95,9\% dos docentes já presenciaram comportamentos violentos entre alunos durante as aulas (TOKUYOCHI et $\mathrm{l}^{4}, 2008$ apud NETTO-MAIA et al. 2013).

Em resposta ao alarmante cenário descrito, a população faz exigências de soluções. E, tanto as reinvindicações, quanto as ações das instituições públicas, são direcionadas para a repressão. Mas, será que, ao aumentarmos a repressão, estaremos construindo a paz? Ao colocarmos policiais dentro da escola para evitar a violência entre os estudantes, garantiríamos que esses estudantes fossem pessoas pacíficas em outros locais de convivência? Então, estaria a escola e seus docentes cumprindo a função de formadores de cidadãos? Para entender um pouco mais sobre o processo de violência e a cultura de paz na escola, buscamos com esse trabalho responder como o professor de Educação Física percebe a Promoção da Cultura de Paz no ambiente escolar. Partimos de um referencial teórico que analisa, num primeiro momento, o fenômeno violência, a violência escolar e suas nuances, e em seguida, adentramos ao tema da Promoção da Cultura de Paz, a partir de uma linha de pensamento que acredita que, se a cultura da violência se constrói cultural e socialmente, a cultura de paz também pode vir a ser construída, a partir de ações intencionalmente planejadas.

\section{REFEReNCIAL TEÓRICO}

\section{Violência}

O conceito trazido pela Organização Mundial da Saúde diz que:

A violência é definida como o uso da força física ou do poder real ou em ameaça, contra si próprio, contra outra pessoa ou um grupo, que resulte ou tenha possibilidade de resultar em lesão,

3 MALTA, Débora Carvalho et al. Vivência de violência entre escolares brasileiros: resultados da Pesquisa Nacional de Saúde do Escolar (PeNSE). Ciências e Saúde Coletiva, v. 15, p. 3053-3063, 2010.

4 TOKUYOCHI, Jorge Hideo et al. Retrato dos professores de educação física das escolas estaduais do estado de São Paulo. Motriz, Rio Claro, v. 14, n. 4. p. 418-428, out./dez. 2008. 
morte, dano psicológico, deficiência de desenvolvimento ou privação (WORLD HEALTH ORGANIZATION, 2002, p. 6).

Sposito (1998, p. 60) conceitua violência como "todo ato que implica na ruptura de um nexo social pelo uso da força. Nega-se assim a possibilidade da relação social que se instala pela comunicação, pelo uso da palavra, pelo diálogo e pelo conflito". Complementa ainda que, também, práticas mais sutis e cotidianas como o racismo e a intolerância e, até, os mecanismos relativos à violência simbólica, são violência, (SPOSITO, 1998).

Percebemos que os atos violentos são formas de diminuição do outro ou de si, manifestando-se sob diferentes roupagens e predominantemente contra grupos minoritários. Em material do Ministério da Saúde encontramos referência sobre tal afirmação:

Ela (a violência social) se manifesta nas discriminações e preconceitos em relação a determinados grupos que se distinguem por sua faixa etária, raça, etnia, seu gênero, suas necessidades especiais, sua condição de portadores de doenças e de pobreza. Assim, crianças e adolescentes negros, mais do que os brancos, estão sujeitos à discriminação; crianças e jovens do sexo masculino, mais do que os do sexo feminino, estão sujeitos à violência fatal; crianças e adolescentes do sexo feminino são mais vitimadas pela violência não letal; deficientes físicos, portadores do HIV/aids e crianças e adolescentes pobres são mais vulneráveis e expostos aos acidentes e violências e aos danos por estes provocados. (BRASIL, 2004, p. 24).
Romper o nexo social significa desunir, desconectar. A violência, então, pode ser entendida como um ato que rompe a união, desassociando as pessoas, rompendo o todo chamado humanidade. Yves de La Taille (2013) afirma que "a sociedade contemporânea é uma sociedade fragmentada e em consequência disso caminha em direção ao tédio, depois ao estresse, à depressão e, por fim, muitas vezes, ao suicídio (uma das formas de violência) ${ }^{5 "}$. Há um ciclo vicioso, onde o fenômeno da fragmentação potencializa o fenômeno da violência e vice-versa.

Outro ponto que nos surpreende negativamente, é o fato de que, como coloca Silva (1997), as várias formas de violência, produzidas no cotidiano da sociedade, parecem não mais indignar a população brasileira. Estaríamos diante do fenômeno chamado de cultura da violência? Segundo Tylor ${ }^{6}$ (apud LARAIA, 1986, p. 25) o vocábulo inglês Culture, "tomando em seu amplo sentido etnográfico é este todo complexo que inclui conhecimentos, crenças, arte, moral, leis, costumes ou qualquer outra capacidade ou hábitos adquiridos pelo homem como membro de uma sociedade". Então, estaríamos cultivando, nos dedicando e nos interessando pela violência? Ainda, o hábito, as crenças, os costumes estariam permeados por esse modo de agir? Marcondes Filho (2001) coloca que sociedade está estruturalmente contaminada, pois os excessos, os arbítrios e os desvios são tolerados e, os que não toleram são perseguidos, isolados ou punidos. Também, afirma que "o 
que torna as formas de violência em cultura é o fato de realizarem a dupla definição de Rousseau: "de serem algo conscientemente ou inconscientemente cultivado dentro de certa comunidade (real ou difusa); e as pessoas serem "educadas" segundo esse procedimento ( p. 21)".

Será que crenças, artes, leis, costumes e hábitos em nossa contemporaneidade estão voltados, consciente ou inconscientemente, para a violência? As corriqueiras expressões como: o país não tem mais jeito; os políticos são todos corruptos; a juventude está perdida; não levo desaforo para casa; se eles (políticos governantes) roubam; eu também posso; além de muros pintados, músicas, filmes, novelas e seriados com conteúdo agressivo, que tratam de traição e violência, mais as diferentes manifestações que circulam a cada minuto nas redes sociais, (talvez essa vírgula seja necessária?) podem estar denunciando essa realidade. Marcondes Filho (2001) em estudo que procura demonstrar que a natureza dos relacionamentos no Brasil é violenta, afirma que haveria uma cultura da violência à medida que a cultura, como Habitus $^{7}$, incorpora as práticas de violência.

\section{Violência e escola}

Aquino (1998) afirma que existem duas tônicas nos estudos sobre violência escolar: uma de cunho sociologizante, que possui como causa fundamental da violência os aspectos culturais, econômicos e políticos, no dado momento histórico; a outra, de cunho psicologizante, que trabalha com a questão da estruturação psíquica dos sujeitos, como a causa fundamental do fenômeno. Segundo o autor, ambas são exógenas à escola, o que geraria uma resignação, posto que o gérmen do fenômeno reside fora da escola, o que levaria sempre à mesma ação perante fatos violentos: o encaminhamento. Encaminhamento para o Serviço de Orientação Educacional (SOE), para a Direção, para outras instituições sócio-educacionais, constituindo-se num "empurra-empurra" que parece não contemplar o processo educativo que compete à escola.

A relação da violência com a escola é tratada sobre dois vieses: a violência na escola e a violência escolar. A violência na escola refere-se, segundo Viana (2002, p. 126), "a toda e qualquer forma de violência que ocorre na escola, mas que não é produzida por ela. Sua fonte é extraescolar". Essa violência está de acordo com a tônica sociologizante dos estudos, em que a causa primeira da violência são as questões estruturais. Como exemplos, temos a invasão de gangues rivais que manipulam alunos e comércio de drogas. E, também, está de acordo com a linha do pensamento psicologizante, quando defende que a violência é algo inerente ao indivíduo. Sebastião, Alves e Campos (2003) afirmam que a violência, nas mais variadas formas, pode ser considerada hoje um elemento estrutural das sociedades industrializadas ocidentais e que a violência na escola, com suas especificidades, faz parte integrante desse fenômeno.

7 Habitus: um sistema de disposições duráveis e transponíveis que, integrando todas as experiências passadas, funciona a cada momento como uma matriz de percepções, de apreciações e de ações. (BOURDIEU, 1983b, p. 65). 
Já a violência escolar, segundo Viana (2002), é uma forma específica de violência, que é gerada pela instituição escolar, ou seja, a escola produz uma violência que é o resultado das suas próprias relações sociais. Como a escola é o resultado de seus atores sociais, visto que ela, como instituição não tem mobilidade própria, professores, alunos, funcionários, pais, etc, são, conscientemente ou não, geradores dessa violência. Nesse sentido Viana (2002, p. 115) afirma que: "a violência escolar é realizada tanto por aqueles que detêm o poder, quanto pelos que estão submetidos a ele". E segundo Silva (1997), psicologicamente, o indivíduo normalmente identifica os problemas no outro, mas raramente reconhece-se como parte deste, ou causador dele.

Corroboramos a ideia de Landim e Araújo (2013), quando afirmam que a escola não pode ser "milagreira" e resolver por completo o problema da violência escolar, mas ela é importante alternativa para revertermos essa realidade que ela própria vivencia, seja na condição de autora, vítima ou como palco da violência.

\section{Cultura de paz}

Para a ONU, conforme a declaração de 1999, “a paz não é apenas ausência de conflitos, mas constitui-se num processo positivo, dinâmico e participativo em que se promova o diálogo e se solucionem os conflitos dentro de um espírito de entendimento e cooperação mútuos" (ORGANIZAÇÃO DAS NAÇÕES UNIDAS, 1999, p. 2).

Dusi, Araújo e Neves (2005, p. 136) definem que:

A paz envolve uma visão de construção, de ação e de investimento pessoal na autotransformação e na transformação do meio, com vistas à dignidade e ao desenvolvimento, sendo caracterizada não por um movimento reduzido de combate a violência, mas algo construído, das mais simples as mais elaboradas ações e interações do cotidiano.

Nessa perspectiva, entendemos que a paz não é um produto pronto, acabado, passível de ser implantada por meio de decretos ou quaisquer formas de determinação estabelecidas através de relações impositivas e verticalizadas. A paz é um processo dinâmico, complexo, partilhado, entrelaçado em redes de relações movidas por uma intencionalidade comum.

Para Milani (2003) a paz não é apenas um intervalo entre guerras; e a mera assinatura de acordos e tratados é insuficiente para construí-la, enquanto os valores de violência, dominação e conflito se mantiverem. É preciso fazer uma relação aproximando a vida na escola, pois boas intenções e belos discursos não bastam para criar relações de paz, respeito e cooperação.

No Artigo $1^{\circ}$ da Declaração sobre uma Cultura de paz, o documento mais contundente sobre a cultura de paz, lançado pela $\mathrm{ONU}$, define que ela é um conjunto de valores, atitudes, tradições, comportamentos e estilos de vida baseados em alguns pontos, entre os quais: respeito à vida, fim da violência, promoção e prática da não-violência por meio da educação, do diálogo e da cooperação; no pleno respeito e promoção de todos os direitos humanos e liberdades fundamentais; no compromisso com a solução pacífica dos conflitos; nos esforços para satisfazer as necessidades de desenvolvimento e proteção do meio-ambiente; na adesão aos princípios de liberdade, justiça, democracia, tolerância, 
solidariedade, cooperação, pluralismo, diversidade cultural, diálogo e entendimento em todos os níveis da sociedade e entre as nações (ORGANIZAÇÃO DAS NAÇÕES UNIDAS, 1999 p. 2).

Buscando alternativas para materializar princípios comprometidos com a construção de uma cultura de paz, Milani (2004) apresenta dois níveis possíveis de ação - o micro, em que qualquer pessoa, por menor ou mais simples que seja sua atuação, pode atuar; e o nível macro, que diz respeito aos processos sociais, estratégias de mudança coletiva, políticas públicas e estruturas institucionais, etc. "Os níveis micro e macro são complementares, interdependentes e precisam ser trabalhados simultaneamente" (p. 24).

O artigo $4^{\circ}$ da Declaração sobre uma cultura de paz reza que "a educação, em todos os níveis, é um dos meios fundamentais para construir uma Cultura de Paz" (ORGANIZAÇÃO DAS NAÇÕES UNIDAS, 1999, p. 2).

Portanto, em consonância com o documento da ONU e com as ideias dos autores que referenciam este estudo, também defendemos que a escola constitui-se em importante espaço/local de fomento e construção de uma outra racionalidade que possa romper com a cultura da repressão e da violência e caminhar ao encontro de uma convivência mais humana e solidária.

Dusi, Araújo e Neves (2005) afirmam que à escola enquanto espaço de manifestações e vivências da realidade, compete a tarefa de promoção da paz, de sua vivência e difusão, apresentando-se como um local privilegiado de observação e intervenção frente à realidade da violência.
O educador tem o direito-dever de educar para a paz, fazendo possível o trânsito de uma cultura, educação, para, sobre, e na paz, que nos permita a todos vivermo-la, como um processo criativo, com repercussões diretas no cotidiano, criando outro mundo: plural e humano (CORREA, 2003). Em frase atribuída a Ghandi, segundo Muñoz (2013) sintetizamos o parágrafo: "Não existe caminho para a paz, a paz é o caminho".

Milani (2003) afirma que, o primeiro passo, para quem desejar atuar de forma consistente na Promoção Da Cultura de Paz, é identificar e superar as premissas que fundamentam o seu modelo mental a respeito dessa temática, como por exemplo, acreditar que a violência é um ente com existência e vontade próprias e na sua unicausalidade, relacionadas a visão psicologizante. Milani (2004) ao estudar três instituições que adotaram a Promoção da Cultura de Paz como norte balizador das ações, identificou como eixo principal em cada uma delas: a inclusão (retorno à escola dos evadidos e expulsos, por exemplo); o protagonismo juvenil (formar adolescentes multiplicadores de saúde, para atuarem na comunidade); e a valorização da diversidade (direção e professores tem uma relação de muita qualidade, almoçando juntos, partilhando as mesas, e sala do diretor aberta com livre acesso dos professores).

Tais constatações, na nossa compreensão, representam situações concretas da possibilidade da construção da cultura de paz e nos mobilizam a melhor compreender como o professor de Educação Física percebe e/ou se insere nas dinâmicas em que violência e paz são tensionadas no cotidiano escolar. 


\section{METODOLOGIA}

O desenvolvimento do estudo foi realizado com base na pesquisa qualitativa. Esta, para Bardin, (2004) compreende um conjunto de diferentes técnicas interpretativas que visam descrever e decodificar os componentes de um sistema complexo de significados. A escolha dos sujeitos foi do tipo intencional por conveniência. Participaram do estudo duas professoras de Educação Física, de uma escola de ensino médio da rede pública estadual do Rio Grande do Sul. As coletas de informações para esse estudo foram realizadas através da análise do Plano Político Pedagógico, de entrevista semiestruturada e observações de campo. O projeto foi submetido inicialmente aos procedimentos éticos legais. As entrevistas foram gravadas em aparelho Smartphone, Nokia, modelo Asha 310, e transcritas posteriormente.

Para realizarmos as análises das informações coletadas, valemo-nos da técnica de Análise de Conteúdo, que, segundo Bardin (2004, p. 38), "procura conhecer aquilo que está por trás das palavras sobre as quais se debruça".

\section{DISCUSSÃO}

A partir das informações coletadas, em relação ao primeiro objetivo, que busca "compreender como o professor percebe as questões de violência e cultura de paz", emergiram as seguintes categorias: violência, situações de violências, violência e paz, e cultura de paz. Em relação ao segundo, "como o professor trabalha as questões de violência em suas ações pedagógicas", emergiu a categoria posição da escola frente à violência. E em relação ao terceiro, "possibilidades de promoção de uma cultura de paz" emergiu a categoria possibilidades. Para preservar a identidade dos interlocutores, designamos os professores como professor "A" $\mathrm{e}$ "B".

\section{Violência}

Analisando os trechos da entrevista encontramos as seguintes definições de violência pelas professoras:

é aquilo que está fora da ordem. Fora da ordem de relação humana de respeito [...]. É quando está fora de um possível equilíbrio. (Prof. A).

é um ato que agride outra pessoa. $O$ ato mesmo. É um ato de agressão. Emocional, psicológico, físico. Isso é uma violência. (Prof. B).

A definição da professora " $A$ " vai ao encontro do entendimento de que a violência busca diminuir o outro, ou seja, quebrar esse equilíbrio entre os seres humanos, que é dado pelo respeito. A professora "B" se aproxima da definição de violência que é referenciada pela OMS, quando esta a define como o uso da força física ou poder real, para causar algum dano ou privação. Sposito (1998) coloca que a violência é um ato que nega qualquer possibilidade de relação social que se instalaria pela comunicação, pelo uso da palavra, pelo diálogo ou pelo conflito. Lesa, enfim, a convivência.

$\mathrm{Na}$ fala da professora "B", outro ponto importante a ser levantado: "ato que agride". Embora haja uma relação entre agressividade e a violência, elas são fenômenos diferentes. A agressividade segundo 
Minayo et al. (2013, p. 23) "ao contrário da violência, inscreve-se no próprio processo de constituição da subjetividade. A transformação da agressividade em violência é um processo ao mesmo tempo social e psicossocial". Muñoz (2013, p. 284) em artigo que destaca a importância da educação para a construção da paz, também frisa que a agressividade não é o mesmo que violência, sendo que ela "forma parte do comportamento humano, como um mecanismo adaptativo e força motora para a autoafirmação física e psíquica do sujeito". O autor entende que a agressividade é inata, enquanto a violência é construída socialmente e, portanto, possível de se desconstruir.

\section{Situações de violência}

Indagamos às professoras sobre terem vivenciado ou presenciado algum tipo de violência. Na resposta de uma das professoras, identificamos a violência simbólica ${ }^{8}$ sendo praticada, tanto pelos alunos, quanto pelos professores:

[...]É aquilo que eles vêm vestidos, muitas vezes é violento. [...]eles não confiam, ainda. [...] eles se armam. [...] assim como alguns professores entram em sala de aula com armadura, também (Prof A).

O uso de símbolos de poder dispensa a força física ou outros meios, mas silencia os protestos, e, no ambiente escolar, seriam exercidos entre os alunos e na relação desses com os professores (ABRAMOVAYe RUA, 2003).

Abramovay e Rua (2003) identificaram que, numa variação de $24 \%$ a $42 \%$, os alunos das capitais do país dizem não gostar da maioria dos alunos, o que generaliza uma situação de desconforto e desconfiança entre todos. Essa ausência de empatia e solidariedade, segundo o autor, estende-se às relações aluno/professor, também. Tanto alunos, quanto professores se armam de alguma forma, para evitar que outros entrem em seus mundos.

A falta de comunicação entre professores e alunos gera revolta por parte destes, afetando, possivelmente a auto-estima dos estudantes, que não aceitam ser ignorados, encontrando ainda uma forte crítica à única preocupação dos professores - repasse de conteúdos -, sem interação com a turma; por outro lado, os professores se sentem desconfortáveis, pois falta o respeito dos alunos, eles comportam-se de maneira autoritária, humilhando e insultando os docentes, além de, em escolas privadas, valerem-se em muitos casos do poder ou prestígio da família, para forçar, até mesmo, demissões (ABRAMOVAY e RUA, 2003).

Outro episódio de violência trazido pela professora foi o disparo com arma de fogo, na aula teórica de Educação Física:

[...] o disparo dentro da sala de aula. Depois que foi liberado, eu fui no pátio da escola e perguntei o que eu estava fazendo aqui?[...] muitas esperanças se foram" (Prof. A).

8 Violência Simbólica: violência suave, insensível, invisível a suas próprias vítimas, que se exerce essencialmente pelas vias puramente simbólicas da comunicação e do conhecimento, ou, mais precisamente, do desconhecimento, do reconhecimento ou, em última instância, do sentimento (BOURDIEU, 2003, p. 7-8). 
Abramovay e Rua (2003) afirmam que as armas chegam em grande quantidade à escola, sendo justificada pelos alunos, como forma de impor respeito, proteção e defesa, e que, esse campo, a qualquer momento, pode se tornar um campo de batalha. Netto-Maia (2013) identificou que muitos professores já vivenciaram algum tipo de violência, até mesmo envolvidos nela, e que muitos não sabem como agir. No caso da professora entrevistada, o episódio envolvendo a arma parece ter fragilizado suas convicções enquanto educadora.

\section{Violência e paz}

Ao discutirmos a representação do que significa violência e paz, as professoras trazem o aspecto dos valores e do ambiente influenciando um ou o outro fenômeno:

...então, no geral, ser bom, ser da paz é ser babaca. Entre eles é. [...] O que é legal é ser esperto. [...] O que é legal é saber se impor (Prof A).

Muñoz (2013) defende que é urgente a necessidade de trilharmos caminhos que tornem realidade a educação em valores, e, dentre estes, a educação para a paz é de suma importância perante o alarmante problema da violência. Afirma ser possível a educação em valores, criando um clima participativo e democrático, através da participação democrática, de hábitos de autonomia e autodeterminação, e criação de espaços de diálogos, compreensão mútuas, solidariedade, cooperação, integração coletiva e discussão objetiva de conflitos. $\mathrm{Na}$ fala da professora se enuncia um certo senso comum, representado há algum tempo atrás pela emblemática "lei de Gerson" que significava levar vantagem em tudo, não importando os meios para atingir os fins. Superar essa ideia deve ser um dos desafios da educação deste nosso tempo!

A professora " $B$ " retrata o ambiente que se constitui como consequência da violência:

A violência tira o sossego. [...] A violência tira o foco do objetivo daquilo que tu quer. Causa uma desarmonia. A paz [...] é o contrário: te possibilita tu trabaIhar melhor todas essas relações, com tranquilidade (Prof. B).

Nesse sentido Abamovay e Rua (2003) identificaram que os alunos não conseguem se concentrar, ficam nervosos, revoltados e perdem a vontade de ir para a escola, em função do fenômeno da violência. Em relação aos professores, no mesmo estudo, os autores identificaram a perda de estímulo para o trabalho, em primeiro lugar, sentimento de revolta em segundo, e dificuldade de concentração como terceira consequência.

Em relação à Paz há uma compreensão mais voltada para o sentimento interiorizado de paz. Para Dusi, Araújo, Neves (2005) a paz vai além dessa concepção interior, ela envolve uma visão de construção, de ação e investimento pessoal na autotransformação e na transformação do meio com vistas à dignidade e ao desenvolvimento. Na mesma linha de pensamento, Minayo (2013), afirma que a transformação da agressividade em violência é um processo que tem a contribuição do ambiente cultural. Por outro lado, Dusi, Araújo e Neves (2005, p. 136) colocam que "o vínculo existente nas relações sujeito-ambiente torna a construção e a vivência da paz a sua 
mais efetiva e eficaz forma de promoção e difusão". Portanto, quer seja na constituição da violência ou na promoção da paz, a conjuntura cultural tem implicações decisivas.

\section{Cultura de paz}

Há algumas aproximações com os conceitos de cultura e paz: "atitude; se colocar no lugar; bem-estar"; contudo os professores trazem a ideia de cultura de paz muito relacionada à sensação, à paz interior. Não há uma manifestação das mesmas no seu sentido de agir, de planejar ações, envolvendo a escola, e até mesmo a comunidade sob os princípios dessa cultura.

Cultura de paz é como uma atitude. [...]é chamar a responsabilidade para si. [...] se colocar no lugar do outro. [...] dar limites às pessoas com uma boa palavra. [...] dar um limite fora do orgulho. (Prof A)

Trabalhar várias questões que levem, que possibilite bem-estar, a paz. No meu caso, que é a Educação Física, como eu posso trabalhar isso? A socialização, né? (Prof. B)

Milani (2003) diz que cultura de paz abrange todos os ideais pelos quais a humanidade anseia, como justiça, igualdade entre os sexos, fim do racismo, tolerância religiosa, equilíbrio ecológico, respeito a minorias, educação universal e liberdade política, trabalhando de forma integrada esses ideais, promovendo as transformações necessárias e indispensáveis para que a paz seja o princípio governante de todas as relações humanas e sociais. As falas das professoras parecem indicar ausência de propósitos e até mesmo de projetos que impliquem em compromisso com o desenvolvimento de uma cultura de paz.

\section{Posição da escola}

Ao serem questionadas sobre a posição da escola em relação às situações de violência presentes no cotidiano, as professoras expressam o que percebem:

Eu acho que a escola se salva do jeito que ela pode, entendeu? [...](Prof A).

Serviço de orientação. [...] Ela tem assim, quando a coisa está demais, mas nunca está demais [...], (Prof. B).

Falas como, "a escola se salva de qualquer jeito"; "serviço de orientação"; "quando a coisa está demais"; demonstram que não há uma linha de ação em consonância com o PPP da escola que norteie o encaminhamento dos problemas de violência. Um exemplo foi o fato presenciado no estágio com a decisão de expulsão do aluno que escondeu a arma do colega que realizou o disparo na sala de aula. Milani (2000) enfatiza que são três as abordagens possíveis pelos diversos atores sociais, diante do fenômeno da violência: uma abordagem repressiva, uma abordagem estrutural e a cultura de paz, colocando que é necessário a escola pensar novas possibilidades de lidar com a violência e novas possibilidades que deem sentido a escola na vida dos alunos. Infelizmente a mais usada é a abordagem repressiva, a qual acrescentaríamos também punitiva, alternativa utilizada no episódio em pauta.

Numa das falas da professora, podemos identificar uma atitude bastante 
corriqueira no cotidiano das escolas, em relação a alguma situação de violência:

[...] dá um problema maior, eu, num primeiro momento eu pedi pra parar. Dependendo da situação eu já dou um grito também (Prof. B).

A atitude da professora de, se necessário for já dar um grito, vai ao encontro do que Bossle e Molina Neto (2009) encontraram em estudo auto-etnográfico, realizado numa escola pública, em que interpretaram algumas manifestações de violência, no interior da escola, a partir do que eles configuraram como "pedagogia do berro", onde tudo se resolve no grito.

Realmente presenciamos, tanto nas salas de aula, quando em outros espaços da escola, como recreio, sala da orientação e, inclusive, sala das direções, o fenômeno do grito como solução para conflitos e indisciplina. Seria essa melhor alternativa? Parece-nos que não. Pois ao resolver questões conflitantes ou indisciplinares por meio "do berro", deixamos escapar a oportunidade de vivenciar com o educando o diálogo, e o valor deste para o estabelecimento do respeito mútuo. Elementos esses significativos para a harmonização social, que possa contribuir com a promoção de uma sociedade pacífica e empática.

\section{Possibilidades}

Embora nas respostas anteriores não se consiga vislumbrar um projeto maior envolvendo o tema, as professoras acreditam como possível a promoção de uma cultura de paz.
Pequenas ações,[...]. Individuais, né. [...] Um querer de $50 \%$ mais um da escola (Prof A).

São várias as possibilidades. [...]. Que a escola trabalha com projetos, né. [...] A escola tem a gincana. [...]. Trabalhos de horta. (Prof. B).

Na reposta da prof. "A", quando menciona pequenas ações, ela visualiza a possibilidade de promoção ao nível micro da construção da paz, ou seja, no âmbito individual, sendo necessário pensar o comportamento, a vida familiar e suas relações na comunidade, local de trabalho e círculo de amizades. Quando a professora "B" fala em projetos, identificamos uma aproximação com o nível macro, que engloba o repensar dos processos sociais, estratégias de mudança coletiva, políticas públicas, estruturas institucionais e programas educativos (projetos, gincanas, hortas) voltados para os valores de paz, exigindo qualificação e experiência.

Outro ponto interessante que colhemos da fala da professora " $A$ " é a colocação de que se $50 \%$ mais um do total dos professores se comprometerem com a promoção de uma cultura de paz, esta se tornará possível. Curiosamente, Milani (2004) analisou três (3) organizações que trabalham com base nos princípios da promoção da cultura de paz: uma escola pública; uma organização não-governamental em parceria com a sercretaria de saúde de São Paulo e uma escola privada internacional. O autor, concluiu que, na escola pública, mesmo havendo apenas metade (50\%) dos professores engajados na proposta da promoção da cultura de paz da diretora, já foi suficiente para produzir mudanças marcantes. 
Em relação à vivências com projetos sobre cultura de paz, no primeiro projeto mencionado pela professora "A", o valor evidenciado e a ser construído para a promoção da cultura de paz é a união, a partir de um exercício de convivência e, no segundo, o convívio e o diálogo são as ferramentas utilizadas para se alcançar o objetivo.

A gente precisa fazer uma ação conjunta para comprar um terreno. [...] balho é voluntário. Então o exercício é o conviver.[...] Agora tem um encontro de diálogo no período do carnaval em 2015 (Prof. A).

Para Boff (2006, p. 32), na filologia da palavra, convivência trata-se de uma "vivência com os outros, jamais sem os outros", que possui três (3) pilares: a participação, a comunhão e a celebração/festas.

Em relação ao diálogo, Milani (2004) ressalta que entre as necessidades e estratégias para a promoção da cultura de paz, a relação do educador-educando deve fundamentar-se nesta habilidade. Porém, "dialogar, é muito mais do que interagir ideias e posturas. É sim, uma competência própria da cultura da paz" (LUZ, 2004, p. 163). Dialogar é aprender a ouvir, e ouvir até o fim o que o outro tem a dizer sem que o interrompamos, compartilhando o silêncio, quando necessário (MARIOTTI, 2001). Segundo Mariotti (2001) a cultura ocidental está automatizada num processo concordo-discordo, o que mostra que não sabemos ouvir. Hunter (2004) afirma que ouvir é uma tarefa de esforço ativo, consciente e disciplinado, para silenciar toda a conversação interna, mas que na maior parte das vezes, ouvimos seletivamente, fazendo julgamentos, pensando em maneiras de terminar a conversa ou direcioná-la de modo mais prazeroso para nós. "Não há diálogo, porém, se não há um profundo amor ao mundo e aos homens. Não é possível a pronúncia do mundo, que é um ato de criação e recriação, se não há amor que a infunda" (FREIRE, 1987, p. 45).

A professora "B" cita como exemplo o Seminário Integrado, atividade da Proposta Pedagógica para o Ensino Médio Politécnico implantada a partir de 2012 em que os professores escolhem um tema relevante, e todas as disciplinas trabalham com ele, culminando numa apresentação final, onde são discutidas várias questões, sejam elas sobre pesquisa ou não.

\begin{abstract}
[...] não é projeto, é seminário integrado, quando surgiu aqui na escola, eu participei. E nós começamos a trabaIhar essas questões. Todos os professores de uma forma ou outra estão integrados nisso no momento. Trabalha-se qualquer questão sobre pesquisa ou não (Prof. B).
\end{abstract}

Embora os seminários sejam uma ferramenta valiosa na construção do conhecimento relacionado à cultura de paz, quando a professora menciona " trabalha várias questões da escola", entendemos que ele ainda não é uma atividade que tenha esse ideal como propósito. Ainda está aquém do que Milani (2003) sugere para construção dessa cultura, quando afirma que a paz deve abranger todos os ideais pelos quais a humanidade anseia e que ela seja o princípio governante de todas as relações humanas e sociais.

\section{CONCLUSÃO}

O estudo demonstrou que a compreensão das professoras sobre a violência 
está relacionada ao rompimento do nexo social, ou seja, da possibilidade da relação social, seja por uma inversão de valores, como coloca a professora "A", seja por um ato de agressão física, emocional ou psicológica, como coloca a professora " $\mathrm{B}$ ". Estas percepções vão ao encontro do que coloca tanto Sposito (1998), quanto a OMS, quando definem que a violência é um ato que causa dano e privações.

Em relação à percepção sobre cultura de paz, há o entendimento, por parte das colaboradoras, de que são mudanças individuais, relacionadas à atitude de chamar a responsabilidade para si, ou para as próprias aulas de Educação Física. Essa visão de cultura de paz se refere ao indivíduo, ao sujeito como promotor da cultura de paz, o que está de acordo com Milani (2004), quando afirma que a cultura de paz precisa ser pensada a nível micro, o qual compreende o comportamento, a vida familiar, a vida comunitária, etc. E encontramos uma referência ao nível macro, relacionado aos processos sociais e coletivos, quando a professora falou em projeto. Lembrando que, segundo Milani (2003), para uma efetiva construção da paz, o nível micro e o nível macro são complementares, sendo um dependente do outro.

$\mathrm{Na}$ forma como são trabalhadas as questões de violência, encontramos (re) ações ao fenômeno da violência. Não existe, nem por parte da escola, nem por parte dos professores, uma intencionalidade para a prevenção do fenômeno, tampouco, para uma promoção da cultura de paz. Apesar disso, as professoras percebem ser possível promover a cultura de paz, trazendo como sugestões ações individuais e desenvolvimento de projetos, buscando que, tanto alunos quanto professores, percebam que é preciso saber conviver.

Enfim, entendemos que há uma compreensão geral do que seja a promoção da cultura de paz, mas ainda não há um conjunto de estratégias, sistematizadas e intencionais, com esse foco. Sugerimos que sejam desenvolvidos projetos educacionais nas escolas, com base nos elementos capazes de promover uma cultura de paz, como por exemplo, a educação pautada em valores a serem avaliados e dimensionados no seu real potencial e eficiência para a promoção dessa cultura.

\section{REFERÊNCIAS}

ABRAMOVAY, Mirian; RUA, Maria das Graças. Violência nas escolas. Brasília: Unesco, 2003.

AQUINO, Júlio Groppa. A violência escolar e a crise da autoridade docente. Caderno Cedes, Campinas, v. 19, n. 47, p. 7-19, dez. 1998.

BARDIN, Laurence. Análise de conteúdo. Lisboa: Edições 70, 2009.

BOFF, Leonardo. Virtudes para um outro mundo possível: convivência, tolerância e respeito. Petrópolis, RJ: Vozes, 2006. BOSSLE, Fabiano; MOLINA NETO, Vicente. No "olho do furacão": Uma autoetnografia em uma escola da rede municipal de ensino de porto alegre.

Rev. Bras. Cienc. Esporte, Campinas, v. 31, n. 1, p. 131-146, setembro, 2009. BOURDIEU, Pierre. Esboço de uma teoria da prática. In. ORTIZ, Renato. Sociologia. São Paulo: Ática, 1983.

BOURDIEU, P. A dominação masculina. 3 ed. Rio de Janeiro: Bertrand Brasil, 2003. BRASIL. Ministério Da Saúde. Violência faz mal à saúde. Brasília, 2004. 
CORREA, Rosângela Azevedo. Cultura, educação para, sobre e na paz. In: MILANI, Feizi Masrour; JESUS, Rita de Cássia Dias Pereira de. Cultura de paz: estratégias, mapas e bússulas. Salvador: Edições Inpaz, 2003. p. 98-141.

DUSI, Miriam Lúcia Herrera Masotti; ARAÚJO, Claisy Maria Marinho de; NEVES, Marisa Maria Brito da Justa. Cultura da paz e psicologia escolar no contexto da instituição educativa. Psicologia Escolar e Educacional, Campinas, v. 9, n. 1, p. 135145, jun. 2005.

FREIRE Paulo. Pedagogia do oprimido. 17. ed. Rio de Janeiro: Paz e Terra, 1987.

HUNTER, James C. O monge e o executivo: uma história sobre a essência da liderança. 2 ed. Rio de Janeiro: Sextante, 2004

LA TAILLE, Yves de. Turista ou peregrino. Campinas, jul. 2013. Disponível em: <vimeo.com:http://vimeo. com/71441803 $>$. Acesso em: 12 ago. 2014.

LANDIM, Maria Neide de Souza; ARAÚJO, Paulo Sérgio Medeiros de. A temática da violência escolar na percepção dos professores. Fortaleza - Ceará, 2013. Disponível em: < http:// professorvirtual.org/site/wp-content/ uploads/sites/2/2013/12/Artigo-Ne... pdf $>$. Acesso em: 8 set. 2014.

LARAIA, Roque de Barros. Cultura: um conceito antropológico. 22. ed. Rio de Janeiro: Jorge Zahar, 2009.

LUZ, Araci Asinelli da. Planejando a cultura de paz e a prevenção da violência na escola. In: MILANI, Feizi Masrour; JESUS, Rita de Cássia Dias Pereira de. Cultura de paz: estratégias, mapas e bússulas. Salvador: Inpaz, 2003. p. $159-171$.
MARCONDES FILHO, Ciro. Violência fundadora e violência reativa na cultura brasileira. São Paulo em Perspectiva. São Paulo, v15, n2, p.20- 27, abr/jun, 2001.

MARIOTTI, Humberto. Diálogo: um Método de Reflexão Conjunta e Observação Compartilhada da Experiência. Thot, São Paulo, n. 76, p. 6-22, 2001.

MILANI, Feizi. Cidadania: construir a paz ou aceitar a violência? In: Cidadania mundial: a base da paz. FREITAS, M. (org.). Planeta Paz. Mogi Mirim, São Paulo. 2000.

MILANI, Feizi. Cultura de paz x violências: papel e desafios da escola. In: MILANI, Feizi Masrour; JESUS, Rita de Cássia Dias Pereira de. Cultura de paz: estratégias, mapas e bússulas. Salvador: Inpaz, 2003. p. 31 - 62.

MILANI, Feizi. Violências x cultura de paz: a saúde e cidadania do adolescente em promoção. 197 f. Tese (Doutorado). Instituto de saúde coletiva, UFBA, Salvador, 2004.

MINAYO, Maria Cecília de Souza et al. Conceitos, teorias e tipologias de violência. In: NJAINE, Kathie; ASSIS, Simone Gonçalves de; CONSTANTINO, Patrícia. (Org.). Impactos da violência na saúde. 2. ed. Rio de Janeiro: Editora Fiocruz, 2013. v. 1, p. 21-42.

MUÑOZ, Manuel Alfonso Díaz. Violência e escola: o desafio ético de educar para a paz. Cultura e Comunidade, Belo Horizonte, v. 8, n. 14, p. 280-295, jul./ dez. 2013.

NETTO-MAIA, Luciana de Lourdes Queiroga et. al. O professor também vivência a violência escolar? Revista de Enfermagem do Centro Oeste Mineiro, v. 3, n. 3, p. 797-803, set/dez. 2013. 
ORGANIZAÇÃO DAS NAÇÕES UNIDAS. Declaração Universal dos Direitos da Criança. 1959. [site]. Disponível em: < http://www.unicef.org/brazil/pt/ resources_10120.htm > . Acesso: 17 nov. 2014

ORGANIZAÇÃO DAS NAÇÕES UNIDAS. Declaração sobre os direitors dos povos à paz. Assembléia geral. no 39/11. 12 de novembro de 1984. [site]. Disponível em: < http://www.unicef.org/brazil/pt/ resources_10120.htm >. Acesso: 17 nov. 2014

ORGANIZAÇÃO DAS NAÇÕES UNIDAS. Declaração sobre uma cultura de paz. n 53/243, 1999. [site]. Disponível em: < http://www.unicef.org/brazil/ pt/resources_10120.htm $>$. Acesso: 17 nov.

ORGANIZAÇÃO DAS NAÇÕES UNIDAS PARA EDUCAÇÃO, A CIÊNCIA E A CULTURA. [Site]. Disponível em: $<$ http://www.unesco.org.br/programas/ index.html > . Acesso em: 08 set. 2014.
SEBASTIÃO, João; ALVES, Mariana Gaio; CAMPOS, Joana. Violência na escola: das política ao cotidiano. Sociologia, Problemas e Práticas, Oeiras, n. 41, p. 37-62, jan. 2003.

SILVA, Aida Maria Monteiro. A violência na escola: a percepção dos alunos e professores. Diálogo, São Paulo, p. 1014, 30 jun. 1997.

SPOSITO, Maria Pontes. A instituição escolar e a violência. Caderno de Pesquisa, São Paulo, v. 104, p. 58-75, 1998.

VIANA, Nildo. Violência e escola. In. VIANA, Nildo et. al. Educação, cultura e sociedade: abordagens críticas na escola. Goiânia: Germinal, 2002.

WAISELFISZ, Júlio Jacobo. Homicídios e juventude no Brasil. Rio de Janeiro: Secretaria Geral da Presidência, 2013. WORLD HEALTH ORGANIZATIO. World reporton violence and health. Geneva: WHO; 2002. 


\section{CULTURE OF PEACE IN PERCEPTION OF PHISICAL EDUCATION TEACHER INSIDE A NETWORK SCHOOL OF EDUCATION RIO GRANDE DO SUL}

\section{SUMMARY}

This study aims to understand how the physical education teacher perceives the culture of peace promotion in the school environment. The theoretical reference analyzes the phenomenon of violence, school violence and its nuances and then deals with the culture of peace promotion, from a view that believes that if the culture of violence is built culturally and socially, the culture of peace It may also come to be built from intentionally planned actions. It is a qualitative research conducted through interviews, field observations and document analysis. Notes that teachers are knowledgeable of the culture of peace, but objective and intentional actions in this direction also are not developed.

Keywords: Physical Education; Culture of Peace; School Violence

\section{CULTURA DE PAZ EN PERCEPCIÓN DE LOS PROFESORES DE EDUCACIÓN FÍSICA DE UNA ESCUELA DE LA RED DE EDUCACIÓN DEL ESTADO DE RIO GRANDE DO SUL}

\section{RESUMEN}

Este estudio tiene como objetivo comprender cómo el maestro de educación física percibe la cultura de la promoción de la paz en el entorno escolar. El marco teórico trata de violencia, violencia escolar y sus matices. También se ocupa de la promoción de la cultura de la paz, creyendo que, si la cultura de la violencia se construye cultural y socialmente, la cultura de la paz puede llegar a ser construida a partir de acciones intencionales. Es una investigación cualitativa realizada a través de entrevistas, observaciones y análisis de documentos. Se nota que los profesores tienen conocimiento de la cultura de paz, pero las acciones objetivas e intencionales en este sentido tampoco se desarrollan.

Palabras clave: Educación Física; Cultura de Paz; Violencia Escolar

Recebido em: abril/2016

Aprovado em: junho/2016 